\title{
SERGANČIŲJŲ PERIFERINIŲ ARTERIJŲ LIGA RIZIKOS VEIKSNIŲ, AMPUTACIJOS PRIEŽASTIES IR LYGIO POVEIKIS KINEZITERAPIJOS EFEKTYVUMUI PO APATINĖS GALŪNĖS AMPUTACIJOS
}

\author{
Patricija Šilinskè, Lina Leimonienė \\ Lietuvos sveikatos moksly universiteto Medicinos akademijos Slaugos fakultetas, \\ Reabilitacijos klinika
}

Raktažodžiai: apatinès galūnės amputacija, periferinè arterijų liga.

\begin{abstract}
Santrauka
Net 65 proc. amputacijų atliekama senyvo amžiaus (60-75 m.) asmenims. Dažniausia priežastis - periferinių arterijų liga (PAL), kurią neretai sukelia cukrinis diabetas (CD) [2]. Žmonèms, kurie serga $\mathrm{CD}$, amputacijos tikimybè yra gerokai didesnè, negu tiems, kurie juo neserga [3]. Tai ìvyksta dèl infekcijos, neuropatijos ir padidejusio PAL paplitimo. Pastebèta, jog pacientams po galūnés amputacijos ị reabilitacijos programą įtraukus fizinị treniravimą, reabilitacijos laikas buvo trumpesnis. Fiziškai aktyvių ar sportinejje veikloje dalyvaujančių pacientų gyvenimo kokybė ir saviverte yra didesnè, nei fiziškai pasyvių asmenų [4]. Tyrimo tikslas - nustatyti sergančiųu PAL rizikos veiksnių, amputacijos priežasties ir lygio itaką kineziterapijos efektyvumui po apatinès galūnès amputacijos. I tyrimą buvo ịtraukti asmenys, atitikę šiuos kriterijus: sergantieji PAL, patyrę apatinès galūnès amputaciją ir atvykę ị sveikatos priežiūros ịstaigą antrajam reabilitacijos etapui. Tyrime

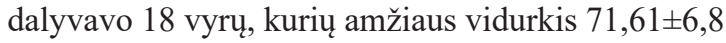
metų. Ištyrus pacientus prieš ir po kineziterapijos, buvo nustatytas pusiausvyros ir èjimo greičio pokytis. Kineziterapijos pabaigoje atlikta duomenų analizé, kurios tikslas - nustatyti, kaip tyrimo rezultatus lèmè rizikos veiksniai: rūkymas, arterinė hipertenzija, $\mathrm{CD}$, amputacijos priežastis ir lygis. Tyrimo metodai. Reikalingai informacijai apie pacientą gauti taikytas anketinès apklausos metodas. Kineziterapijos efektyvumui vertinti taikytas Berg'o pusiausvyros testas (pusiausvyrai ivertinti) ir "Stotis ir eiti“ testas (ejjimo greičiui ịvertinti).
\end{abstract}

Rezultatai. Po kineziterapijos procedūrų tiriamujų pusiausvyra pagerèjo nuo $27,89 \pm 4,378$ iki $34,94 \pm 3,827$ balų $(\mathrm{p}<0,05)$, o ejjimo greitis - nuo $38,28 \pm 4,663$ iki $31,89 \pm 4,861$ sekundžių $(\mathrm{p}<0,05)$. Tiriamujų pusiausvyra ir èjimo greitis nepriklauso nuo amputacijos lygio, rūkymo, arterinès hipertenzijos ir $\mathrm{CD}(\mathrm{p}>0,05)$.

\section{İvadas}

Viena iš seniausių chirurginių procedūrų, žinomų nuo Hipokrato laikų, yra apatinès galūnès amputacija. Kojų amputacijos buvo atliekamos esant bet kokio laipsnio audiniu nykimui. Per metus JAV atliekama apie 140000 amputacijų, iš kurių daugiau nei pusè - apatinès galūnès amputacija [1]. Daugiausia (65 proc.) amputacijų atliekama senyvo amžiaus (60-75 m.) žmonèms. Dažniausia priežastis - PAL, kurią neretai sukelia CD. Dėl šios priežasties atliekama net 25-90 proc. amputacijų [2]. Žmonemms, kurie serga CD, amputacijos tikimybė gerokai didesnè, negu tiems, kurie juo neserga [3]. Tai ịvyksta dèl infekcijos, neuropatijos ir padidejusio PAL paplitimo. Nors per daugelį metų chirurginè technika tam tikrą laiką nesikeitè, perioperacinès priežiūros, protezavimo ir reabilitacijos medicinos pažanga padejjo gerokai pagerinti pacientų, kuriems atlikta amputacija, gyvenimo kokybę [1]. Pastebèta, jog pacientams po galūnès amputacijos ị reabilitacijos programą ịtraukus fizinị treniravimą, reabilitacijos laikas buvo trumpesnis. Fiziškai aktyvių ar sportinèje veikloje dalyvaujančiu pacientų gyvenimo kokybė ir savivertė yra didesnè, nei fiziškai pasyvių asmenų [4].

Tyrimo tikslas: nustatyti sergančiujų PAL apatinès galūnès amputacijos rizikos veiksnių, priežasties ir lygio įtaką kineziterapijos efektyvumui.

\section{Tyrimo objektas ir metodai}

Tyrimui gautas Lietuvos sveikatos mokslų universiteto Bioetikos centro leidimas Nr. BEC-SR(M) -206). Jo galio- 
jimo metu Palangos reabilitacijos centre „Pušynas“ ištirta 18 vyrų, sergančių PAL, patyrusių apatinès galūnès amputaciją ir atvykusių antrajam reabilitacijos etapui. Tiriamujų amžiaus vidurkis $71,61 \pm 6,8$ metų. Ištyrus pacientus prieš ir po kineziterapijos, nustatytas pusiausvyros ir ejimo greičio pokytis. Kineziterapijos pabaigoje atlikta duomenų analizè, siekiant nustatyti, kaip tyrimo rezultatus lèmè rizikos veiksniai: rūkymas, arterinè hipertenzija, CD, amputacijos priežastis ir lygis. Reikalinga informacija apie pacientą gauta anketinès apklausos metodu, tiriamujų pusiausvyrai įvertinti taikytas Berg'o pusiausvyros testas, ejjimo greičiui įvertinti - „Stotis ir eiti“" testas. Tyrimo duomenų analizè atlikta naudojant statistikos paketo SPSS (angl. Statistical packet for social sciences) 19.0 versiją. Diagramoms atvaizduoti naudotasi MS Excel 2010 programa. Kadangi duomenys nèra pasiskirstę pagal normalujji dèsni, tos pačios tiriamujjų grupès skirtumų palyginimui prieš ir po intervencijos taikytas Mano-VitneyVilkoksono (angl. Mann-Whitney-Wilcoxon test) kriterijus. Skirtumai laikyti patikimais, jei paklaidos tikimybè mažesnè, nei $\mathrm{p}<0,05$.

\section{Rezultatai}

Vertinant tiriamujų, patyrusių apatinės galūnès amputaciją, pusiausvyrą, naudota Berg'o skalè. Tiriamujų pusiausvyra prieš kineziterapiją îvertinta $27,89 \pm 4,378$ balais, o po kineziterapijos šis rodiklis padidèjo 7,06 $\pm 0,59$ balais ir siekè $34,94 \pm 3,827$ balus ( $\mathrm{p}<0,001)$ ( 1 pav.).

Siekiant ịvertinti tiriamujų èjimo greitị prieš ir po kineziterapijos, buvo palyginti „Stotis ir eiti“ testo rezultatu vidurkiai. Pacientams tyrimo metu rekomenduota patiems pasirinkti saugiausią èjimo greitị. Kineziterapijos pradžioje tiriamujų èjimo greičio vidurkis buvo $38,28 \pm 4,663$ sekundès, o po kineziterapijos taikymo jie testą atliko $6,38 \pm 0,34$ se-

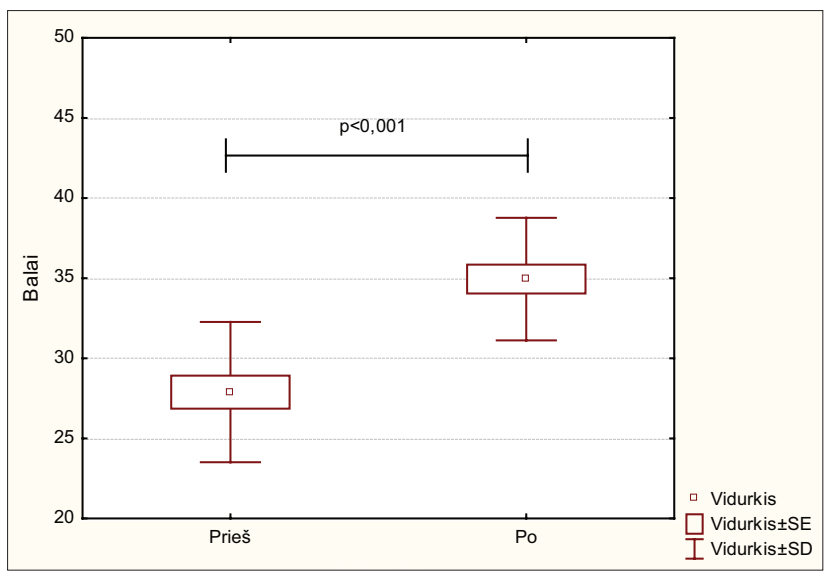

1 pav. Tiriamujų pusiausvyros pokyčiai $(\mathrm{p}<0,001)$ prieš ir po kineziterapijos, balais. kundėmis greičiau, t.y. per $31,89 \pm 4,861$ sekundes $(p<0,001)$ (2 pav.).

Tiriamujų, kuriems apatinès galūnès amputacija buvo atlikta žemiau kelio sąnario, Berg'o pusiausvyros vertinimo rezultatai prieš kineziterapiją buvo $31(27-35 ; 30,80)$, po kineziterapijos $39(32-40 ; 37,10)$ balai, pokyčio vidurkis $6,30 \pm 2,35$ balų $(\mathrm{p}<0,05)$. Patyrusių amputaciją šlaunies lygyje, duomenys prieš kineziterapiją buvo $24(20-27 ; 24,25)$, po kineziterapijos $31(29-38 ; 32,25)$ balas, pokyčio vidurkis $8 \pm 2,50$ balų $(\mathrm{p}<0,05)$. Rezultatai tarp grupių nesiskyre $(\mathrm{p}>0,05)$.

Nustatyta, jog tiriamujų, kuriems apatinė galūnė amputuota žemiau kelio sąnario, ,Stotis ir eiti““ testo ejimo greičio rezultatai prieš kineziterapiją buvo $36(30-39 ; 35,10)$, po kineziterapijos $28,50(24-33 ; 28,50)$ sekundès, pokyčio vidurkis $6,60 \pm 1,42$ balų $(\mathrm{p}<0,05)$. Patyrusių amputaciją šlaunies lygyje, rezultatai prieš kineziterapiją buvo 42(39-46; 42,25), po kineziterapijos $37,00(37-39 ; 26,13)$ sekundès, pokyčio vidurkis $0,612 \pm 1,55$ balų $(\mathrm{p}<0,05)$. Rezultatai tarp grupių nesiskyrè $(\mathrm{p}>0,05)$.

Atlikus duomenų analizę, nustatyta, kad rūkančiu tiriamujjų Berg'o pusiausvyros vertinimo skalès rezultatai prieš kineziterapiją buvo 27(20-35;27), po kineziterapijos 34(29$39 ; 34,94)$ balai, pokyčio vidurkis $6,83 \pm 2,44$ balai $(\mathrm{p}<0,05)$. Nerūkančių tiriamujų rezultatai kineziterapijos pradžioje buvo $29,50(25-35 ; 29,67)$, pabaigoje - 38,50(32-40; 37,17) balai, pokyčio vidurkis $7,5 \pm 2,81$ balai $(\mathrm{p}<0,05)$. Rezultatai tarp grupių nesiskyrè ( $\mathrm{p}>0,05)$.

Tyrimo metu nustatyta, kad rūkančių tiriamujų ,Stotis ir eiti“" testo ejjimo greičio rezultatai prieš kineziterapiją buvo $39(20-35 ; 27)$, po kineziterapijos 33(29-39;34,94) sekundès, pokyčio vidurkis $-6,5 \pm 1,08$ sekundès $(p<0,05)$. Nerūkančių tiriamujų rezultatai kineziterapijos pradžioje buvo $36,50(25-$

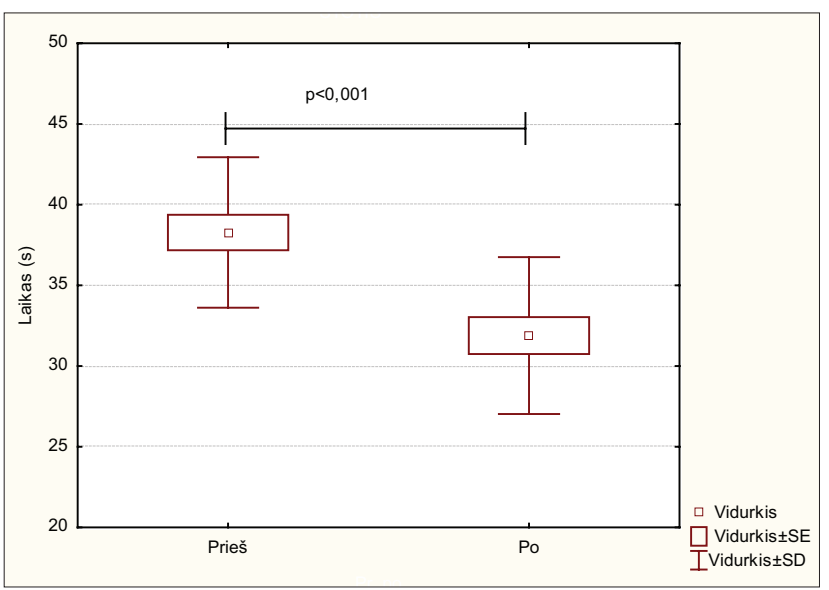

2 pav. Tiriamųų ėjimo greičio pokyčiai $(p<0,001)$ prieš ir po kineziterapijos. 
$35 ; 29,67)$, pabaigoje $28,50(32-40 ; 37,17)$, pokyčio vidurkis $6,16 \pm 2,13$ sekundès $(p<0,05)$. Rezultatai tarp grupių nesiskyrè $(\mathrm{p}>0,05)$.

Tiriamujų, sergančių arterine hipertenzija, Berg'o pusiausvyros testo rezultatai prieš kineziterapiją buvo $27(20$ $34 ; 26,60)$, po kineziterapijos 34(29-39;34) balai, pokyčio vidurkis $7,40 \pm 2,55$ balai $(\mathrm{p}<0,05)$. Tiriamujų, kurie nesirgo arterine hipertenzija, rezultatai kineziterapijos pradžioje buvo $35(33-35 ; 34,33)$, pabaigoje $40(39-40 ; 39,67)$ balų, pokyčio vidurkis $5,33 \pm 1,52$ balai $(\mathrm{p}>0,05)$. Rezultatai tarp grupiu nesiskyrè $(\mathrm{p}>0,05)$.

Tiriamujjų, sergančių arterine hipertenzija, „Stotis ir eiti“" testo ejimo greičio rezultatai prieš kineziterapiją buvo $39(32-46 ; 39,40)$, po kineziterapijos 33(26-39; 33) sekundès, pokyčio vidurkis $-6,40 \pm 1,50(\mathrm{p}<0,05)$. Tiriamujų, kurie nesirgo arterine hipertenzija, rezultatai kineziterapijos pradžioje buvo 30(30-38;32,67), pabaigoje 25(24-30;26,33), pokyčio vidurkis $-6,33 \pm 1,52$ sekundès $(p>0,05)$. Rezultatai tarp grupių nesiskyrè ( $\mathrm{p}>0,05)$.

Tiriamujų, sergančiu CD, Berg'o pusiausvyros testo rezultatai prieš kineziterapiją buvo $27(20-32 ; 26,89)$, po kineziterapijos 34(29-39;33,89) balai, pokyčio vidurkis $7 \pm 2,34$ balai $(\mathrm{p}<0,05)$. Tiriamujų, kurie nesirgo $\mathrm{CD}$, rezultatai kineziterapijos pradžioje buvo $27(23-35 ; 28,89)$, pabaigoje $-38(29-40 ; 36)$ balai, pokyčio vidurkis $7,11 \pm 2,80(\mathrm{p}<0,05)$. Rezultatai tarp grupių nesiskyrè ( $p>0,05)$.

Tiriamujų, sergančių CD, „Stotis ir eiti“ testo ejjimo greičio rezultatai prieš kineziterapiją buvo 39(30-46;38,22), po kineziterapijos 33(24-39;31,78) sekundès, pokyčio vidurkis $6,44 \pm 1,6(\mathrm{p}>0,05)$. Tiriamujų, kurie nesirgo $\mathrm{CD}$, rezultatai kineziterapijos pradžioje buvo 38(32-44;38,33), pabaigoje 32(26-39;32) sekundès, pokyčio vidurkis $6,33 \pm 1,32$ sekundès $(p<0,05)$. Rezultatai tarp grupių nesiskyrè $(p>0,05)$.

\section{Išvados}

1. Po kineziterapijos tiriamujų pusiausvyra pagerejo $(\mathrm{p}<0,05)$.

2. Po kineziterapijos tiriamujų èjimo greitis pagerèjo $(\mathrm{p}<0,05)$.

3. Tiriamujų pusiausvyra ir ejjimo greitis nepriklauso nuo amputacijos lygio, rūkymo, arterinès hipertenzijos ir $\mathrm{CD}(\mathrm{p}>0,05)$.

\section{Literatūra}

1. Cuff RF, Simmons JM. The management of lower extremity amputations, current surgical therapy. 2017:1110-1114.

2. Agarwal S, Sud K, Shishehbor MH. Nation wide trends of hospital admission and outcomes among critical limb ischemia patients: from 2003-2011. J Am Coll Cardiol 2016; 67(16): 1914-1916. https://doi.org/10.1016/j.jacc.2016.02.040

3. Li Y, Burrows NR, Gregg EW, et al.Declining rates of hospitalization for nontraumatic lower-extremity amputation in the diabetic population aged 40 years or older: U.S., 1988-2008. Diabetes Care 2012;35(2):273-277.

https://doi.org/10.2337/dc11-1360

4. Bragaru M, Dekker R, Geertzen, JH, Dijkstra PU. Amputees and sports: a systematic review. Sports Med 2011;41(9):721-740. https://doi.org/10.2165/11590420-000000000-00000

\section{INFLUENCE OF RISK FACTORS, CAUSE OF AMPUTATION AND LEVEL OF AMPUTATION ON PHYSIOTHERAPY EFFICIENCY IN PATIENTS WITH PERIPHERAL ARTERIAL DISEASE AFTER AMPUTATION OF LOWER LIMB P. Šilinskè, L. Leimonienė}

Keywords: amputation of lower limb, peripheral arterial disease.

Summary

65 percent amputations are performed in the elderly patients (60-75 years). The most common cause is peripheral vascular disease, which is often caused by diabetes mellitus (DM) [2]. People with DM are more likely to have amputation than those who do not. [3]. This occurs due to infection, neuropathy and increased incidence of peripheral arterial disease. Patients have been shown to have a shorter rehabilitation period after limb amputation, when physical training has been included in a rehabilitation program. The quality of life and self-esteem of patients who participate in physically active life is higher than in non-participants [4].

The aim of the study was to determine the influence of risk factors, cause of amputation and level of amputation on the efficiency of physiotherapy in persons with peripheral arterial disease after amputation of lower limb. Patients meeting the following criteria were enrolled: peripheral arterial disease, lower limb amputation, and admission to a second phase of rehabilitation. The study included 18 men with a mean age of $71.61 \pm 6.8$ years. Changes in balance and walking speed were observed in patients before and after physical therapy. Data analysis was performed at the end of physiotherapy to determine how the study results were based on risk factors (smoking, arterial hypertension, diabetes mellitus), cause of amputation, and level of amputation. The study used a questionnaire survey to obtain patient information needed for the study, the Berg balance test, and the station and walk test for walking speed.

Results. After physiotherapy the balance of subjects improved from $27.89 \pm 4.378$ to $34.94 \pm 3.827$ points $(\mathrm{p}<0.05)$. After physical therapy, walking speed improved from $38.28 \pm 4.663$ to $31.89 \pm$ 4.861 seconds $(\mathrm{p}<0,05)$. The subjects' balance and walking speed are independent of amputation, smoking, arterial hypertension and diabetes mellitus $(\mathrm{p}>0,05)$.

Correspondance to: patricija.silinske@gmail.com

Gauta 2019-11-27 